\title{
Coping with diversity: Insights into the qualitative evaluation of a mentoring program
}

\author{
HILDEGARD WENZLER-CREMER*
}

Institute for Psychology, University of Education Freiburg, Kunzenweg 21, 79117, Freiburg, Germany

\section{THEMATIC ARTICLE}

Published online: October 28, 2020

(C) 2020 The Author(s)

\section{ABSTRACT}

The aim of the study is to give an insight into the evaluation of the program "Mentor Migration SALAM Spielen Austauschen-Lernen-Achtsam-Miteinander" (Playing-Sharing-Learning-Attentively-Together). Students striving for a teaching degree or studying Social education at the University of Education Freiburg, mentor a child from a migrant or a refugee family for a period of 9 months. Some of the evaluation results are presented here. Based on different instruments like a questionnaire, open questions, interviews, reports, and minutes of the supervision meetings the mostly qualitative data are analysed and categorized. The article focuses on the impacts on the students: They gain a better awareness for intercultural encounters, and get insights into milieus they usually would not have. So especially the competences 'Coping with Difference' and 'Professional pedagogical Skills' will be investigated. The Intercultural Competence Model of Deardorff gives the theoretical background.

\section{KEYWORDS}

diversity, intercultural competence, migrant children, mentoring, qualitative evaluation

\section{INTRODUCTION}

Classroom diversity means differences in nationality, gender, religion, social status, parents' income, capabilities etc. (Strasser, 2016, p. 28 ff.; Walgenbach, 2014, p.12). For teachers and other educational staff, it is important to recognize the heterogeneity as well as to respect and

\footnotetext{
*Corresponding author. Email: hildegard.wenzler-cremer@ph-freiburg.de
} 
deal with each child as an individual. A difference in culture is only one attribute of diversity and is often overemphasized. Supporting migrant and other disadvantaged children in our educational system is an important task towards enhancing their chances for graduation. Mentoring programs (Heinzel, Garlichs, \& Pietsch, 2007; Mentoring.org) are one way of supporting and encouraging disadvantaged pupils. Simultaneously the mentors involved benefit to a great extent. It is a good opportunity for students who wish to work in the educational field, to be confronted with the reality of migrant children and their families of various social classes they are not familiar with. It can function as an eye opener to learn about their needs, their economic and social situation, their beliefs and desires.

The program: "Mentor Migration SALAM- Spielen-Austauschen-Lernen-AchtsamMiteinander" (Playing-Sharing-Learning-Attentively -Together) was founded in 2009 at the University of Education in Freiburg, Germany. Students striving for a teacher's degree or a degree in Social Education mentor a child for a period of 9 months. They spend 2-3 h of leisure time a week together. The aim is to support children from migrant and other underprivileged families and to give the mentors the opportunity to use their pedagogical skills and to reflect on the experiences they make. Two aspects are characteristic for the program: Firstly, as the mentors are assigned to only one child so they can develop an intensive relationship with that child and its family. Secondly, the program helps to expand the child's horizons, to gain a wider knowledge of its surroundings, the city quarter they live in, and the city itself. The main objective is not to do homework with the children and support them in their academic performance, nor to do special language. The coming together and interacting of mentors and pupils offers many learning opportunities (Garlichs, 2004; Leu, 2014; Pietsch, 2010). The children are challenged to communicate, they have to agree upon the choice of activities with the mentors; they explore new places and spaces; they learn something about their mentor's life. The mentors' role is not narrowly defined, so they take on different roles with the children; for some they are like a big sister, a friend, a teacher (Goldner \& Mayseless, 2008).

The mentors, on the other hand, gain an awareness of how to act in intercultural encounters; they gain insights into milieus they would usually not know nor have the opportunity to enter. They can assist the families with questions regarding the German educational system. The children participating in the program come from very diverse situations: Some have only recently migrated to Germany and still live in accommodation reserved for refugees; others are from families where the parents are already for a long time in Germany but only know German poorly, others are children having multiple siblings or whose parents are divorced; some children are from well to do families, but their German needs to be improved. 50-80 tandems of mentors and pupils a year and approximately 700 in total have been involved since 2009 . The Freiburg University of Education, the city of Freiburg and five primary schools cooperate in this program.

\section{METHODS}

This paper presents part of the qualitative evaluation of the Mentoring Program SALAM. Data like interviews, group discussions, student reports and student questionnaires with open questions have been collected and evaluated since 2009. Wenzler-Cremer (2016a, p. $245 \mathrm{ff}$.) describes the different survey instruments. Here we additionally present parts of an online 
survey which was conducted in 2017. 325 former mentors have been contacted, 92 of them completed the questionnaire with open questions in full. This corresponds to a response rate of nearly $30 \%$. Unlike a quantitative survey, the intention of a qualitative study is not to find out statistical regularities and probabilities, but to reconstruct the actor's perspective and to find out connections and patterns in order to understand their meaning (Kruse, 2014 p. 45). The data material was prepared, if necessary transcribed, signed and read into the Maxqda program (Kuckartz, 2014). A code tree was developed and the material coded with the help of this program. Categories were generated deductively from previous knowledge and special literature as well as inductively from the data material in line with the qualitative content analysis. Some passages were additionally evaluated by text analysis. In the following, selected results are presented with the focus on the mentors' intercultural experiences. Also, some parts of the answers from the Alumni survey 2017 are quoted. More original quotations are presented in Wenzler-Cremer (2016a) and Wenzler-Cremer (2016b).

\section{Theoretical background: The Intercultural Competence Model of Deardorff}

Managing diversity in the classroom requires intercultural competence (Brunner \& Ivanova, 2015, p. 19 ff.; Strasser, 2016, p. 39 ff.). Being able to interact successfully with people from different backgrounds, different cultures, different classes, religions, sexual orientations etc. should be a basic requirement for teachers and other pedagogical staff. Learning to avoid misunderstandings, to be able to recognize a child's potential, and to reach a good understanding with their parents and families, being able to manage conflicts etc. are all essential qualifications for teachers which enable children to have a successful school career and teachers to have a satisfying job. The theoretical framework for working intercultural competent in the classroom is provided by the model of intercultural competence (Deardorff, 2009). It distinguishes between five elements: (a) Attitudes: like respect, openness, curiosity and tolerating ambiguity. (b) Knowledge: cultural self-awareness, culturally specific knowledge, understanding other world views and sociolinguistic awareness (c) Skills necessary to reach internal and external outcomes which are the goal of intercultural competence: observation, listening, evaluating, analysing, interpreting, relating. (d) Internal Outcomes: flexibility, adaptability, ethno relative perspective and empathy. (e) External Outcomes: the effective and appropriate behaviour and communication in intercultural situations (Deardorff, 2009).

\section{RESULTS}

Selected results are presented below. They are deepened and specified by original quotations from the data material including also the alumni survey 2017. After each period (the end of the school year) the students were asked open questions, for example: What does the experience to mentor a migrant child mean for you? To what extent has your perception changed? In the alumni survey 2017 the former mentors were e.g. asked: What do you remember most about the child and the family? To what extent has your participation in the mentoring program influenced your student/professional/personal career? Other statements are collected from tutorials of the program over many years. The data of the qualitative study were assigned to the following main categories: Gaining professional competence; dealing with otherness; changing views and attitudes. 


\section{Professional Learning: the mentors have the opportunity to gain professional competences}

Building a trustful mutual relationship. When the mentors are asked, what they have learned during the program, they usually name: building a relationship with a child, learning to break the ice, communicating and interacting adequately even when the child is shy, anxious, aggressive, impertinent etc.; setting limits, motivating the child, finding out what activities they want to do together, supporting the child expressing its interests and considering what might benefit the child.

In my professional life, as in the mentoring program many things are important, the development of a good relationship, trust in each other, the pointing out of alternative possibilities to act. By the mentoring program my pedagogical skills have been strengthened, which I can further develop in my second part of the teacher training and in professional everyday life. A good relationship with the children is essential in order to be able to work with them. Even small things are enough to develop trust. AM_50_10 ${ }^{1}$

Also in a relationship based on trust there are difficult situations that need to be overcome. Rules have to be established and limits to be set (Müller-Kohlenberg, 2018, p. 109 ff.).

Through mutual openness we have grown together, trust has been established. She was open to my world, I to hers. I had to set limits for her, deal with strengths and weaknesses ((...)), a friendship has developed. OMA2_5_97²

Increasing the understanding for the child and its family. Mentors learn to better understand how a child thinks and feels. They learn to know the impact of a child's background and that each child is an individual.

I gained sensitivity and high motivation to learn more about the learner's stories and backgrounds; I do not shy away from home visits or creative solutions to overcome language barriers; I realized the importance of parental contact and a communication at eye level. AM_70_10

For most of the students this is their very first contact with a migrant family. They report that at the beginning they were curious, open minded and prepared to make new experiences (Wenzler-Cremer, 2016a, p. 79) but sometimes they were anxious and cautious. They realized that skills like listening, observing, analysing, evaluating and relating to others, are basic pedagogical and analytical skills to develop empathy and to cope with situations and challenges they face during the program. During the tutorials, their experiences are discussed and reflected so that new skills, knowledge and competences can be developed.

For my studies, I learned in the tutorials to reflect and to question my self-perception. I learned that my perception is only a special interpretation of reality. AM_6_10

\section{Managing cultural and other differences - Dealing with otherness}

Germany nowadays is an immigrant society and this is also evident in the classroom (Brunner \& Ivanova, 2015, p. $19 \mathrm{ff}$.). Dealing with otherness is a great challenge for all working in the

\footnotetext{
${ }^{1}$ Signature AM_50_10 means: Alumni Survey, Mentor 50, question 10.

${ }^{2}$ Signature OMA2_5_47 means: open questions to mentors in period A2, question no. 5, chapter 97. See Wenzler-Cremer (2016a, p. 259).
} 
pedagogical field. Different rules, different expectations, different ways of life make the interaction exciting, but sometimes also difficult. Differences are very often accompanied by strong emotions: they may make us happy, curious, interested, angry, anxious, disappointed etc. According to the interviews, reports and the answers to the open questions etc. (Wenzler-Cremer, 2016a, p. $63 \mathrm{ff}$.) the mentors are shocked, surprised, curious and sometimes amazed to see the poverty, the way the children are brought up, the way of media consumption, the role setting in the families.

how one feels $l$ when one is an outsider in the family $l$ and is not accepted $l$ and what $l(-)$ how one behaves in general $l$ and how one feels in general $l$ yes $l$ if one comes across it like that IMA_3_106 ${ }^{3}$

When everyone present except them speaks another language, say Arabic, they might feel excluded, because they do not understand a word. They are afraid of being rejected either for personal reasons or just for being German. They feel out of place and uncomfortable. They fear that family members will speak about them when using their own language. Those mentors who are from a migrant background fear rejection because they are not from the same country or the ethnic background. Their code of conduct which is culturally imprinted may not be valid in this context. Some mentors observe that the rules in the family are different to those they know.

In the beginning, I felt very uncomfortable when father, mother, sister, brothers and my child spoke Kurdish and I was there and didn't understand a word. But when they noticed that I was interested in the Turkish culture etc. a little ice was broken. However, the parents still only spoke in Kurdish. OMB2_3_258

In some tandems, mentors report in the tutorials they are challenged by the difference between their standard of punctuality and reliability and that of the family's. They complain that families forget the appointment and they cannot meet with the child. Over time most of the mentors realize that they usually succeed in learning to adapt to the situation as it is or in reaching a change, so that their appointments are taken more seriously. The mentors learn to question some rules and become aware of their own cultural background, because some differences are easier to recognize in contrast. Some of the mentors also tend to draw political conclusions:

The participation in the program sensitized me to refugee policy in Germany and the EU... the experience helps me today in my second part of the teacher training and will have impacts on my professional life. To a certain extent, my work has also made me more politically active and given me an insight into the other side of the refugee policy, namely the side of the people affected. AM_28_10

\section{Changing views and attitudes}

The mentors' expectations and beliefs. Most of the mentors have a middle-class background. As only $12 \%$ of the students in Germany come from an educationally deprived parental home (Middendorff et al., 2016, p. 28), so it is likely that we have approximately a similar number in our student group. That means, not only cultural but also socioeconomic differences become salient. The statements presented here inform about the expectations and first observations of the students.

Large families with many children, traditional male/female roles, often financial difficult situation, little knowledge of German, hospitality extreme! OME1_7_63.

${ }^{3}$ IMA means Interview with a mentor in period A; the transcription rules see Wenzler-Cremer (2016, p. 261) 
This is confirmed by the experience in the tutorials where we ask the students about the differences they perceive between the children's families and their own families. These perceptions have been regularly reflected upon in order to counteract the danger of stereotyping. The mentors enter into a new world and are faced with otherness. The following statements are aggregated from the data material used in Wenzler-Cremer (2016a). Of course, these statements should not be confused with a sociological description of the families participating in the programme. It is by no means the case that the families correspond to the image expressed by the students when starting the mentorship. After the first meeting with the child and its family the students often comment on for instance how small and crowded the homes are and what poor quality the furniture is: no toys, little money, large television screens, mobile phones, play stations; some of them observe that their migrant family of one ethnic group (e.g. Lebanese) live in the same block of flats with other families from that ethnic group and are only interested in having contact with their own ethnic group. By emphasizing the cleanliness of the flat and the friendliness of the parents towards the mentors and the caring of the fathers towards their children they give a hidden insight into their expectations and their view of migrants. When asked what they expected, they usually deny having any specific expectations probably in order not be seen as being prejudiced. Some do, however, express their rather stereotypical expectations about migrants and their families openly.

Admittedly, I had enormous prejudices about children or families with a migration background. For example, I had the following (exaggerated) thoughts: children who come from families in which the parents hardly speak German, have a lot to do with the media and have unfavourable social contacts, can only show behavioural problems at school. OMB2_1_14

These stereotypes may be briefly put together in the following image: migrants mostly look different from native Germans, they have a name which is unfamiliar in Germany, they are poor, unable to speak German, they avoid contact with Germans and are only interested in their own ethnic group. In the course of the program, the mentors learn to see their child's family as one of the many ways how migrant families live in Germany. They realize that many things are not as they expected and that they used attributes without questioning them. The mentors recognize that the way the children are brought up and how mass media are used; the eating habits and the handling of everyday issues is different to their own background but also different between the migrant families. Most of the mentors are young women who are greatly surprised by the gender roles they experience in 'their' families. It is often difficult for them to accept these differences and this leads to many discussions as to whether this is really culturally shaped behaviour.

Most of the mentors are young women who are greatly surprised by the gender roles they experience in 'their' families. It is often difficult for them to accept these differences and this leads to many discussions as to whether this is really culturally shaped behaviour.

The mother is still a young woman... When it was particularly hot she wore the same clothes at home as I did ... Also the hair was dyed and straightened. When she is in public she wears a headscarf. The father, who has a strict and sometimes aggressive reputation as a Muslim father, is also different than I expected. He is very kind to the children and also to his wife. OMB_2_5_197

Sometimes the students do not dare to suggest certain activities and avoid talking about certain topics, because they expect the child or its parents would be against it: for example, visiting the Cathedral of Freiburg with a non-Christian child; going swimming with a Muslim girl. They are surprised when the child or its parents have no problem with these suggestions. In these situations, they realize that they must question their preconceived ideas. 
Identifying and changing stereotypes and prejudices. The mentors sometimes face situations, where 'their' child is the target of prejudice. Mentors report of such incidents, for example when they ride the tram together. People gaze at them or make derogatory remarks. Sometimes comments are made that might be well-intentioned, but can still subtly devalue the child, comments like: 'It is very nice of you to care for a child like this.' There are different strategies in coping with such a situation: ignoring it, leaving the place, protecting the child and answering back. On reflection, however, often the mentors also realize that they themselves are not free from prejudice. One mentor told of how 'her' child was accused of stealing at school. She was not surprised, and then realized that she herself held the assumption because the child came from an immigrant background that she was more likely to be predestined to become a thief. Another mentor told of her feelings before entering refugee accommodations for the first time: she was afraid of being rejected, of being faced with aggressiveness and meeting criminals, and then she was overwhelmed by the friendliness she experienced. The following interview quote and the text analysis of this passage shows the details:

naturally for example at the beginning $l$ as I had the first contact with the family l I felt a bit queasy $l$ (.) going by myself to the refugee housing $l$ (-) because there are different prejudices $l$ how people behave there l ((smiles shyly)) l kind of aggressive l criminal $l$ so the current prejudices that are around $l$ (.) umm l (.) naturally $l$ I had them at the beginning as well (.)l but this for example was dropped completely $l$ during the project $l$ so it was a completely different relationship $l$ to (-) umm (.) walking over there as it was before l(.) it was NOT $l$ that all of them are criminal l ((laughs)) but the people all of them were super kind l they were thankful l they were happy l (-) umm: and yes such l such little stereotypes emerged $l$ now and then during the whole project 1 IM_11_253

Text analysis:

- Depersonalization ('there are'; 'there were always'; 'that are around'; 'but this for example was dropped') which is shown in using passive constructions and in rare use of personal pronouns - Markers of uncertainty ('umm'; 'so kind of; 'naturally'; nonverbal: 'smiles shyly') are used. The speaker does not feel at ease talking about prejudices.

- Connection to prejudices, supposed common ground of knowledge about prejudices to migrants ('Yes, aggressive, criminal'; 'these naturally I had at the beginning as well') The student confesses her own prejudices which makes her conversion more believable.

- The 'current prejudices' have a direct effect on the student. She does not feel at ease when going to the refugee's housing for his first time ('at the beginning as I had the first contact with the family, I felt a bit queasy (.) going by myself to the refugee housing').

- Self-positioning of the narrator: at first, she identifies with the socially predominant prejudices ('naturally I had them at the beginning as well') But this changes during the time. After the experience of contact she presents herself as adaptive and willing to learn. ('but this for example was dropped completely during the project')

- It strikes that so called 'current prejudices' are diminished and belittled ('little ones'). A hedging language is prevalent ('kind of; 'that are around'). The word 'naturally' suggests that prejudices are normal. They seem to belong to human's nature and are therefore excusable.

- Positioning of the inhabitants of the refugee housing as members of a homogeneous group ('all') by assignment of generalized characteristics categorizing them as 'aggressive' and 'criminal'. - the student puts the 'current prejudices' in contrast to her own experience: 'criminal' vs. 'super kind'; 'aggressive' vs. 'thankful and happy.' Using the superlative ('super') and an 
accumulation of positive attributes appears like a compensation to her previous statements ('but the people all of them were super kind, they were thankful, they were happy')+. (WenzlerCremer, 2016b, p. 373)

Cultural attributes are one way of explaining behaviour. Culture is often used as a static category in the process of culturalization. When the mentors observe that the parents have difficulties in dealing with school matters they tend to explain this with cultural difference. Also, a different way of rearing children, the distribution of tasks or the role models within the family are considered to be only caused by cultural reasons. Sometimes the fathers are described as being authoritarian and their Macho-behaviour is criticized in subtle ways by being attributed to their culture. In general, the mentors are cautious in making definite statements about the parents' behaviour. But when parenting is evaluated, they tend to view most differences as culturally determined.

Perceiving the heterogeneity of life situations. At the beginning of the program the mentors often have a very monolithic view of migrant families, but in time they realize that the category 'migrant' is filled very differently. They understand that it makes a difference how long the migrant family has been in Germany, what culture they come from, the religion they belong to, their status in Germany, their right of residence (temporary, or permanent or a rejected asylum seeker), the parents' educational background, the family situation. During the exchange with other mentors in the tutorials they listen to very different stories and become aware that it is important to perceive the individuality of each child and family. Also, when they openly reflect their images of migrants they notice that they have to correct their own view about migrants. Being in contact with a single child and its desires, needs, fears and pleasures, they comprehend that as a teacher they need to see the individual child rather than just viewing it as part of the group.

Some of the students taking part in the Alumni Survey, report that taking part in this program had a great influence for their further occupational decisions.

The program has definitely influenced my decision to work as a social worker at school where I deal very much with migrant children. The program gave me insight into the life of the family I accompanied. That has expanded my perspective on different life worlds. AM_23_10

Understanding the special situation of children with migration background. Understanding the role and impact of one's own culture on behaviour and communication includes analysing and evaluating one's culturally shaped behaviour and thinking. Mentors who are able to build a good relationship with the child and its family gain cultural awareness through information transmitted by storytelling and by discussing similarities and differences of what they observe or experience together. By watching and talking, they learn a lot about different cultural backgrounds. For example, they observe that parents understand the language of a letter sent to them by their child's school, but they do not understand the concept of their role expected by the school. Teachers in Germany expect parents to continuously support the children's learning process. Migrant parents usually expect the teachers to be responsible for the performance of the children in school. These experiences are appreciated by former students as this quotation from the alumni survey shows:

The project had an influence on my personal development to the extent that I was able to make my first... experiences with a family with a migration background. For the first time, I gained deeper insights into their world and got to know the challenges that this family faces in social, financial or linguistic terms. I would therefore say that this project extended my personal horizon 
of experience. However, these experiences have certainly also sensitised me to my professional work as a teacher of children from different social backgrounds and especially of refugee children. AM_64_10

Everybody interprets the world and what happens in life from his own point of view. However, if one accepts that other people have a different view of the world and therefore consider things differently, one has to conclude that one's own perspective is relative. In this program the mentors have the opportunity to reflect on cultural bound rules and behaviour. Whether the mentors are able to come to a deeper understanding of the new culture they face, depends on the openness of both the mentors and the families and also how fluently they can converse with one another. Feeling welcome is the primary condition. Understanding the other's world view does not succeed in every case, especially when mentors do not feel accepted by the child or the family or when they do not get enough feedback about their own behaviour.

\section{CONCLUSIONS}

Our qualitative research focusses on the impacts on the mentors participating in the program. The entire qualitative data material including detailed text analyses of numerous interview passages with students is documented in Wenzler-Cremer (2016a). The conclusions drawn in the following are based on this evaluation. A quantitative evaluation of a similar program (Balu and $\mathrm{Du}$ ) has been published by Kosse, Deckers, Schildberg-Hörisch, and Falk (2016). It focuses on the consequences of sponsorship programmes for the participating pupils and shows that sponsorship is able to promote social behaviour and self-efficacy.

In my qualitative studies, it could be shown that mentors have the chance learning to tolerate ambiguity, they need to have a high degree of flexibility: like learning to deal with a situation, for example, when agreements made in advance are not adhered to, as the child has changed its mind. Learning to deal with such situations increases the mentors' professional competence. They gain adaptability and flexibility. Empathy is enhanced when mentors learn to question their own frame of reference and to learn to take a new stand on norms and values of both their own and of someone else's culture.

Behaving and communicating appropriately and effectively in intercultural situations is an objective which never can be achieved completely, and the acquisition of intercultural competence is a dynamic process. There are times when mentors believe they are moving a step backwards and therefore they need encouragement. Building a good relationship with children from different backgrounds, supporting them, and coming into contact with migrant families succeeds only when the mentors have already gained aforementioned skills, attitudes and knowledge mentioned above. The point of reference changes and at the end of the program the mentors usually assess themselves as being better able to behave culturally sensitive. One way we observe this change is when the farewell party is being prepared and the mentors request that different cultural rules are respected. Appropriate behaviour includes that the cultural norms of the different cultures are taken seriously. Difficulties arise when basic attitudes on both sides like respect, openness and curiosity are missing.

The SALAM program offers mentors the opportunity to gain knowledge and to develop their competences. Learning by doing: surprises, positive changes, success, feelings of happiness, difficulties and disappointments are all part of the experience. The program receives very good 
feedback from the mentors, the teachers, the parents and the children. Difficulties have occurred in very few tandems, for example a child is disappointed, as his mentor has underestimated the responsibility and burden she has assumed and therefore proves unreliable. Mentors sometimes realize their own limitations and bad time management. These difficulties can however be dealt with by supervision in such a way that all parties can learn from this situation. Very rarely has a family cancelled its participation in the program because they were disappointed with a mentor or because they were afraid of giving an outside person too much insight into their family. One should emphasize the importance of a good supervision for the mentors and the success of the program. When the mentors are able to openly discuss their experiences, and reflect on them, then the program is indeed of great benefit to all involved.

Ethics: The study procedures were carried out in accordance with the Declaration of Helsinki. The Faculty of educational science (University of Education, Freiburg) approved the study.

Funding sources: No financial support was received for this study.

Authors' contribution: There is no co-authorship in this article. I am the only author of this article.

Conflict of interest: The author declares no conflict of interest.

\section{ACKNOWLEDGEMENTS}

No additional acknowledgements.

\section{ABOUT THE AUTHOR}

Hildegard Wenzler-Cremer holds a degree as teacher and as master of psychology and received her PhD in psychology from the University of Freiburg. She worked as a teacher and school psychologist in Germany and as an adult educator in Indonesia. Since many years she has been teaching psychology at the University of Education in Freiburg. Her special interests and research focus are social psychology, especially the study of heterogeneity, cross cultural relations and discrimination. She works with the Program "Mentor Migration SALAM- Spielen-AustauschenLernen-Achtsam-Miteinander" (Playing-Sharing-Learning-Attentively -Together), she initiated 2009.

\section{REFERENCES}

Brunner, M., \& Ivanova, A. (2015). Praxishandbuch Interkulturelle LehrerInnenbildung. Schwalbach: Debus- Pädagogik Verlag.

Deardorff, D. (2009). The SAGE handbook of intercultural competence. Thousand Oaks: Sage Publications. 
Garlichs, A. (2004). Kinder verstehen lernen. Ein Versuch im Rahmen des Kasseler Schülerhilfeprojektes. In B. Koch-Priewe (Ed.), Grundlagenforschung und mikrodidaktische Reformansätze zur Lehrerbildung (pp. 235-251). Klinkhardt: Bad Heilbrunn/Obb.

Goldner, L. \& Mayseless, O. (2008) Juggling the roles of parents, therapists, friends and teachers - A working model for an integrative conception of mentoring. Mentoring \& Tutoring: Partnership in Learning, 16(4), 412-428.

Heinzel, F., Garlichs, A., \& Pietsch, S. (Eds.). (2007). Lernbegleitung und Patenschaften: Reflexive Fallarbeit in der universitären Lehrerausbildung. Bad Heilbrunn/Obb: Klinkhardt.

Kosse, F., Deckers, T., Schildberg-Hörisch, H., \& Falk, A. (2016). The formation of prosociality: Causal evidence on the role of social environment. Discussion Paper No. 9861. Bonn: Institut Zukunft der Arbeit. http://ftp.iza.org/dp9861.pdf (accessed 6 March 2020).

Kruse, J. (2014). Qualitative Interviewforschung. Weinheim: Beltz Juventa.

Kuckartz, U. (2014). Qualitative text analysis. Thousand Oaks: Sage.

Leu, H. R. (2014). Non-formales und informelles Lernen -unverzichtbare Elemente frühpädagogischer Professionalisierung. In Deutsches Jugendinstitut e. V. (Ed.), Weiterbildungsinitiative Frühpädagogische Fachkräfte (WiFF Expertisen, Bd. 40). München: DJI. Online: http://www.weiterbildungsinitiative. de/uploads/media/Exp_Leu_web.pdf (accessed 6 March 2020).

Mentorin.org Website:https://www.mentoring.org (accessed 6 March, 2020).

Middendorff, E., Apolinarski, B., Becker, K., Bornkessel, P., Brandt, T., Heißenberg, S., et al. (2016). Die wirtschaftliche und soziale Lage der Studierenden in Deutschland. 21. Sozialerhebung des Deutschen Studentenwerks durchgeführt vom Deutschen Zentrum für Hochschul- und Wissenschaftsforschung. Berlin: Bundesministerium für Bildung und Forschung http://www.sozialerhebung.de/download/21/ Soz21_hauptbericht.pdf (accessed 6 March 2020).

Müller-Kohlenberg, H. (2018). Handbuch Mentoring für Grundschulkinder. Balu und Du - 53 Bausteine für Theorie und Praxis. Ibbenbüren: Münstermann.

Pietsch, S. (2010). Begleiten und begleitet werden. Praxisnahe Fallarbeit. Ein Beitrag zur Professionalisierung in der universitären Lehrerbildung. Kassel: kassel university press GmbH.

Strasser, J. (2016). Pädagogische Professionalität im Zeichen kultureller Vielfalt. In V. Schurt, W. Waburg, V. Mehringer, \& J. Strasser. Heterogenität in Bildung und Sozialisation. Opladen: Budrich.

Walgenbach, K. (2014). Heterogenität - Intersektionalität - Diversity in der Erziehungswissenschaft. Opladen: Budrich.

Wenzler-Cremer, H. (2016a). Studierende und Kinder lernen voneinander. Ein Patenschaftsprogramm an Freiburger Grundschulen. Erfahrungen -Reflexionen - Rahmenbedingungen. Freiburg: Lambertus.

Wenzler-Cremer, H. (2016b). Dealing with diversity: A qualitative evaluation of the program mentor migration SALAM. In C. Roland-Lévy, P. Denoux, B. Voyer, P. Boski, \& W. K. Gabrenya , Jr. (Eds.), Unity, diversity and culture. Proceedings from the 22nd Congress of the International Association for cross-cultural psychology. https://scholarworks.gvsu.edu/iaccp_papers/172 (accessed 9 October, 2020).

Further information about the program you find under: https://www.ph-freiburg.de/salam/ (25 November, 2019).

Open Access. This is an open-access article distributed under the terms of the Creative Commons Attribution-NonCommercial 4.0 International License (https://creativecommons.org/licenses/by-nc/4.0/), which permits unrestricted use, distribution, and reproduction in any medium for non-commercial purposes, provided the original author and source are credited, a link to the CC License is provided, and changes - if any - are indicated. 